\title{
Synthesis of Cotton from Tossa Jute Fiber and Comparison with Original Cotton
}

\author{
Md. Mizanur Rahman, ${ }^{1}$ Md. Rezaur Rahman, ${ }^{2}$ Sinin Hamdan, ${ }^{1}$ Md. Faruk Hossen, \\ Josephine Chang Hui Lai, ${ }^{2}$ and Fui Kiew Liew ${ }^{1}$ \\ ${ }^{1}$ Department of Mechanical and Manufacturing Engineering, Faculty of Engineering, Universiti Malaysia Sarawak, \\ 94300 Kota Samarahan, Sarawak, Malaysia \\ ${ }^{2}$ Department of Chemical Engineering and Energy Sustainability, Faculty of Engineering, Universiti Malaysia Sarawak, \\ 94300 Kota Samarahan, Sarawak, Malaysia
}

Correspondence should be addressed to Md. Mizanur Rahman; 14020009@siswa.unimas.my

Received 6 March 2015; Accepted 24 March 2015

Academic Editor: Vijay K. Thakur

Copyright (C) 2015 Md. Mizanur Rahman et al. This is an open access article distributed under the Creative Commons Attribution License, which permits unrestricted use, distribution, and reproduction in any medium, provided the original work is properly cited.

Cotton fibers were synthesized from tossa jute and characteristics were compared with original cotton by using FTIR and TGA. The FTIR results indicated that the peak intensity of $\mathrm{OH}$ group from jute cotton fibers occurred at $3336 \mathrm{~cm}^{-1}$ whereas the peak intensity of original cotton fibers occurred at $3338 \mathrm{~cm}^{-1}$. This indicated that the synthesized cotton fiber properties were very similar to the original cotton fibers. The TGA result showed that maximum rate of mass loss, the onset of decomposition, end of decomposition, and activation energy of synthesized cotton were higher than original cotton. The activation energy of jute cotton fibers was higher than the original cotton fibers.

\section{Introduction}

In recent years, lignocellulosic materials have grown to be more attractive to the material engineering sectors. These materials, comprising lignin, hemicellulose, and cellulose, have become alternatives to conventional materials. This is due to their environmentally friendly nature and lignocellulosic materials are derived from plants. If the cellulose resources can be fully utilized, much energy can be saved and the environmental pollution can be decreased [1].

Jute is a natural biodegradable fiber, largely produced in India, China, and Bangladesh. In recent years, the development of biodegradable materials from renewable sources has increased [2]. Jute fibers are durable with many advantages, which include low cost, low density, and light weight. Jute fibers are conventionally used as packaging material and carpet backing. Nowadays, jute fiber of improved qualities has attracted its use in different areas, namely, technical textiles, jute gunny sack, jute gunny bag, jute yearn, household textiles, and so forth [3]. Therefore, it is important to develop new products from jute to regain its economic importance. Original cotton fiber is a natural soft fiber obtained from the boll of the cotton plant.

The largest producing areas of cotton are China, India, Pakistan, Bangladesh, Republic of Uzbekistan, Brazil, Australia, Greece, and Syria. Original cotton is stable with many advantages such as low cost, light weight, and easy possessing. The original cotton fibers are conventionally used in medical sector and household textiles. Presently, original cotton fibers are increasingly used in different items, like paper, fiber pulp, food casing, textile mills, spinning mills, knitting mills, and so forth. The original cotton production, however, is less than the actual demand. Therefore, synthesized cotton fibers can be used to fulfill the high demand for original cotton.

Acetic acid and alkali processing is an effective alternative method to fabricate jute cotton fibers [4]. This method also includes dewaxing and delignification. The fabricated cotton fibers derived from jute fibers possess improved properties [5]. The synthesized jute cotton fibers can be used for diverse purposes. In this present work, a new technique and chemical 
process were developed to prepare cotton from jute fibers, and the result was compared with the characteristics of original cotton fiber.

\section{Materials and Methods}

2.1. Materials. Chemicals used in this study were ethanol approximately $96 \% \quad\left(\mathrm{C}_{2} \mathrm{H}_{6} \mathrm{O}\right)$, hydrogen peroxide $35 \%$ $\left(\mathrm{H}_{2} \mathrm{O}_{2}\right)$, supplied by Brightchem Sdn Bhd. Malaysia, toluene $\left(\mathrm{C}_{6} \mathrm{H}_{5} \mathrm{CH}_{3}\right)$, acetic acid (glacial) $100 \%\left(\mathrm{CH}_{3} \mathrm{COOH}\right)$, titanium (IV) oxide $\left(\mathrm{TiO}_{2}\right)$, and potassium hydroxide (solid $\mathrm{KOH})$, supplied by Mallinckrodt Baker, Inc., Sweden. The jute fibers were collected from Bangladesh Jute Research Institute (BJRI), Dhaka, Bangladesh.

2.1.1. Fiber Extraction. The raw jute fibers were cleaned and then washed with tap water to remove dust and other undesirable elements. After that, the jute fibers were airdried for two days under direct sunlight. The middle parts of the jute fibers were taken and chopped into lengths of approximately $3 \mathrm{~mm}$. Then, the chop fibers were placed in a forced air convection oven for drying to remove the moisture content, with a temperature of $105^{\circ} \mathrm{C}$ for 24 hours to ensure that all the moisture has evaporated.

2.1.2. Dewaxing. The dewaxing was done by applying the Leavitt-Danzer method. In this process, two types of chemicals were used, namely, toluene $\left(\mathrm{C}_{6} \mathrm{H}_{5} \mathrm{CH}_{3}\right)$ and ethanol $\left(\mathrm{C}_{2} \mathrm{H}_{6} \mathrm{O}\right)$, with ratios of $2: 1$. The extraction process was done using the extraction column (Soxhlet extractor, Round Bottom Flask, Liebig Condenser, Heater, Membrane, and Thermometer). Then, the chopped jute fibers were immersed in the extraction column. This process was continued for 3 hours at $150^{\circ} \mathrm{C}$. The collected fibers were later placed in the forced air convention oven for 24 hours at $75^{\circ} \mathrm{C}$.

2.1.3. Delignification. The delignification was implied using acetic acid $\left(\mathrm{CH}_{3} \mathrm{COOH}\right)$ and hydrogen peroxide $\left(\mathrm{H}_{2} \mathrm{O}_{2}\right)$ in present titanium oxide $\left(\mathrm{TiO}_{2}\right)$ in a round bottom vector vessel. Then, the dewaxed jute fibers were placed in the round bottom vessel. This process was continued for 3 hours at $130^{\circ} \mathrm{C}$. After this, the collected fibers were carefully washed and placed in the forced air convention oven for 24 hours at $70^{\circ} \mathrm{C}$.

2.1.4. Alkali Treatment. Potassium hydroxide (6\%) (KOH) was placed in $1000 \mathrm{~mL}$ of conical flax and the delignified jute fibers were immersed in the solution for eight hours at $30^{\circ} \mathrm{C}$ and $60^{\circ} \mathrm{C}$, respectively. After that, the collected samples were carefully washed and placed in the forced air convention oven for 24 hours at $70^{\circ} \mathrm{C}$. Dried fibers used as synthesis cotton fibers characterization are shown in Figure 1.

\subsection{Microstructural Analysis}

2.2.1. Fourier Transform Infrared (FTIR) Spectroscopy. The infrared spectra of the synthesized cotton fibers from jute and original cotton fibers were recorded on a Shimadzu FTIR Spectrophotometer with dynamic alignment system sealed

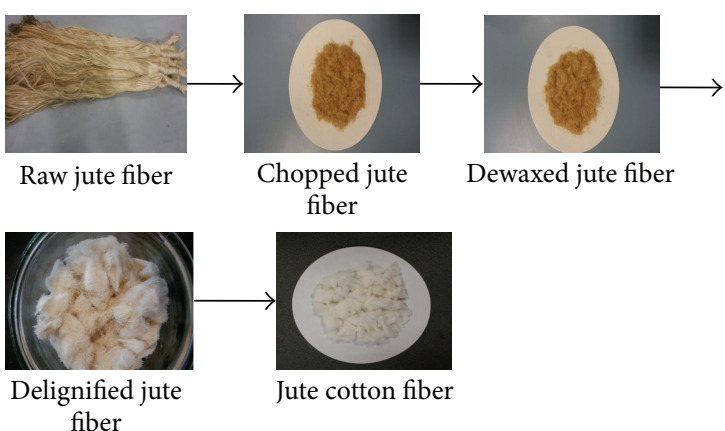

FIgURE 1: Flow chart of the synthesized jute cotton fibers.

interferometer with autodryer and wavenumber range was 350 to $7,800 \mathrm{~cm}^{-1}$. The obtained spectra are presented and discussed in Section 3.

2.2.2. Thermogravimetric Analysis (TGA). Thermogravimetric analysis (TGA) was used to study the thermal stability of synthesized cotton fibers from jute fibers and original cotton fibers. The thermal stability analysis was performed using Perkin-Elmer thermal analyzer (TGA). The specimen $(10 \mathrm{mg})$ was heated from room temperature to $800^{\circ} \mathrm{C}$ at a dynamic heating rate of $5^{\circ} \mathrm{C} / \mathrm{min}$ under $\mathrm{N}_{2}$ using a flow rate of $100 \mathrm{~mL} / \mathrm{min}$.

\section{Result and Discussion}

3.1. Fourier Transform Infrared (FTIR) Spectroscopy. The FTIR spectroscopic analyses of the cotton fibers from jute and original cotton fibers are shown in Figure 2. The wavenumber from 3600 to $3000 \mathrm{~cm}^{-1}$ corresponded to the stretching of $\mathrm{H}$ bonds in the $\mathrm{OH}$ groups $[6,7]$. The IR spectrum showed the peak intensity of jute cotton fibers at $3336 \mathrm{~cm}^{-1}$ of $\mathrm{OH}$ groups whereas the original cotton fibers peak intensity was recorded at $3338 \mathrm{~cm}^{-1}$.

Stretching of the $\mathrm{C}-\mathrm{H}$ group of synthesized jute cotton fibers occurred at $2897 \mathrm{~cm}^{-1}$ while the original cotton fibers showed stretching at 2890 to $2362 \mathrm{~cm}^{-1}$ [8]. The $\mathrm{C}=\mathrm{O}$ absorption band for jute cotton occurred at $1654 \mathrm{~cm}^{-1}$ and the original cotton fibers absorption band occurred at $1648 \mathrm{~cm}^{-1}$ [9]. The absorption band of synthesized jute cotton and original cotton fibers at 1313 and $1321 \mathrm{~cm}^{-1}$ can be attributed to the symmetrical deformation of $\mathrm{NO}_{2}$ in the cellulose azo compound [10]. Therefore, the FTIR results proved that both synthesized jute cotton fibers and original cotton fibers possess similar properties.

3.2. Thermogravimetric Analysis (TGA). Thermogravimetric analysis (TGA) was carried out on the synthesized cotton fibers and original cotton fibers to determine the thermal stability. The thermal stability of synthesized cotton fibers and original cotton fibers is shown in Figure 3. The weight losses of synthesized cotton fibers and original cotton fibers can be illustrated in three stages: (1) dehydration of absorbed moisture and water $\left(<200^{\circ} \mathrm{C}\right),(2)$ the breaking of the cellulose 
TABLE 1: Thermal characteristics of jute cotton fibers and original cotton fibers.

\begin{tabular}{lcccccccc}
\hline Sample names & $\begin{array}{c}T_{i} \\
\left({ }^{\circ} \mathrm{C}\right)^{\mathrm{a}}\end{array}$ & $\begin{array}{c}T_{m} \\
\left({ }^{\circ} \mathrm{C}\right)^{\mathrm{b}}\end{array}$ & $\begin{array}{c}T_{f} \\
\left({ }^{\circ} \mathrm{C}\right)^{\mathrm{c}}\end{array}$ & $\begin{array}{c}W_{T_{i}} \\
(\%)^{\mathrm{d}}\end{array}$ & $\begin{array}{c}W_{T_{m}} \\
(\%)^{\mathrm{e}}\end{array}$ & $\begin{array}{c}W_{T_{f}} \\
(\%)^{\mathrm{f}}\end{array}$ & $\begin{array}{c}\text { Activation energy, } E_{a} \\
\left(\mathrm{~J} /{ }^{\circ} \mathrm{K}\right)\end{array}$ \\
\hline Jute cotton fibers & 200 & 301 & 673 & 88.44 & 82.87 & 43.58 & 59.09 \\
Original cotton fibers & 39 & 296 & 492 & 81.32 & 71.74 & 35.10 & 52.25 \\
\hline
\end{tabular}

${ }^{\mathrm{a}}$ Temperature corresponding to the beginning of decomposition.

${ }^{\mathrm{b}}$ Temperature corresponding to the maximum rate of mass loss.

${ }^{\mathrm{c}}$ Temperature corresponding to the end of decomposition.

${ }^{d}$ Mass loss of temperature corresponding to the beginning of decomposition.

${ }^{\mathrm{e}}$ Mass loss of temperature corresponding to the maximum rate of mass loss.

${ }^{\mathrm{f}}$ Mass loss of temperature corresponding to the end of decomposition.

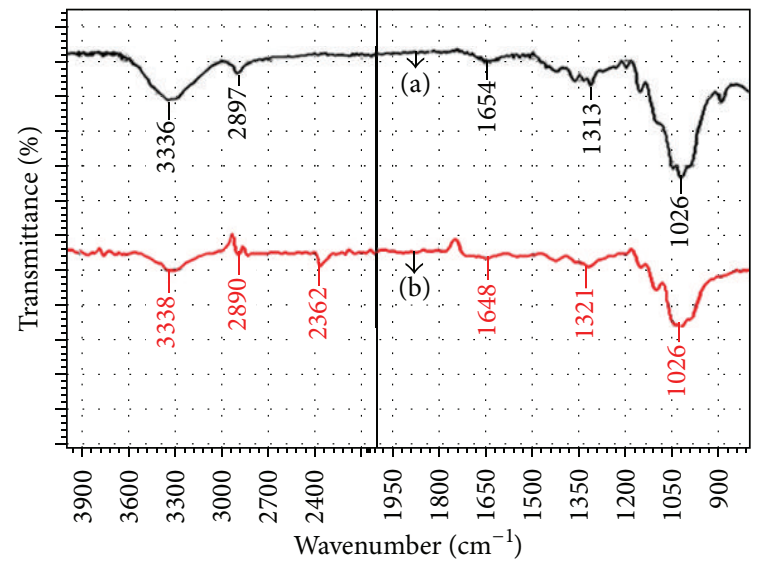

FIGURE 2: FTIR spectra of (a) jute cotton fiber and (b) original cotton fiber.

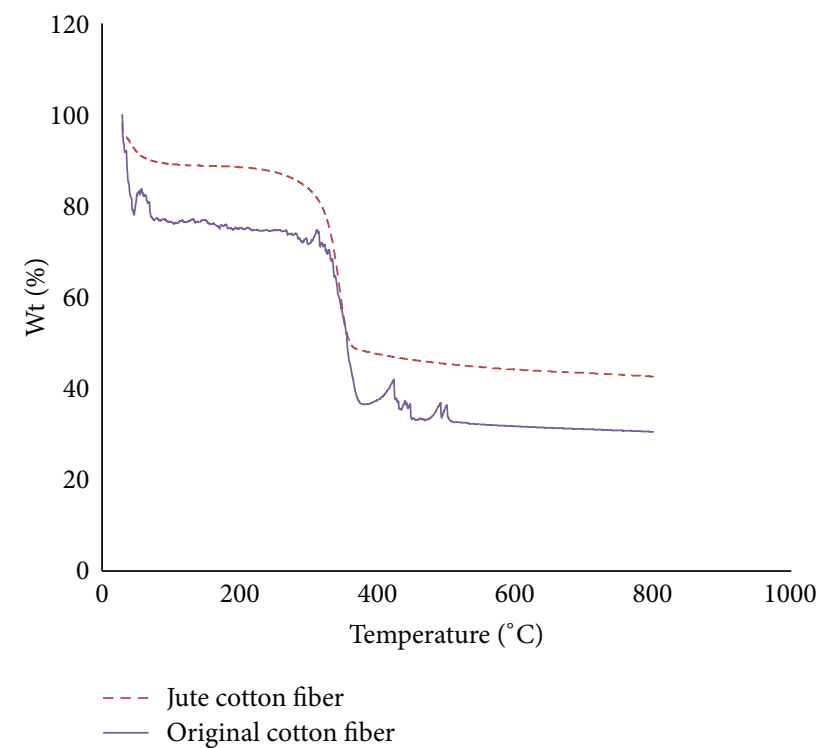

FIGURE 3: TGA curves of jute cotton fibers and original cotton fibers.

chain of $\mathrm{C}-\mathrm{C}$ and $\mathrm{C}=\mathrm{O}\left(200 \sim 380^{\circ} \mathrm{C}\right)$, and finally (3) aromatization $\left(>380^{\circ} \mathrm{C}\right)$, the residual chair formation [11].

From the thermogravimetric analysis on synthesized cotton fibers, it is anticipated that dehydration is approximately
$4.6 \%$ of water. According to Rahman et al. [12] there is no degradation up to $160^{\circ} \mathrm{C}$. Above this temperature, the thermal property decreases gradually and decomposition occurs. The initial and final temperature decompositions $\left(T_{m}, T_{f}\right)$ of jute cotton fibers were slightly higher than that of original cotton fibers which is shown in Table 1. The larger activation energy showed higher stability. The activation energy of jute cotton fibers was slightly higher than the original cotton fibers. Therefore, it can be assumed that the synthesized jute cotton fibers and original cotton fibers possess similar properties regarding thermal stability.

\section{Conclusions}

In this study, jute cotton fibers were synthesized by chemical processes. The FTIR spectrum showed that synthesized jute cotton fibers characteristic band was very similar to the original cotton fibers. The TGA result also showed that the maximum rate of mass loss, onset of decomposition, end of decomposition, and activation energy for synthesis jute cotton fibers were slightly higher than original cotton fibers. It can be concluded that synthesized cotton fiber characteristics were similar to the original ones.

\section{Conflict of Interests}

The authors declare that there is no conflict of interests regarding the publication of this paper.

\section{Acknowledgments}

The authors would like to acknowledge the Ministry of Higher Education of Malaysia and Universiti Malaysia Sarawak for their financial support, Grant no. ERGS/02 (08)/860/2912 (12).

\section{References}

[1] Y. D. Wu, J. M. He, Y. D. Huang, F. W. Wang, and F. Tang, "Oxidation of regenerated cellulose with nitrogen dioxide/carbon tetrachloride," Fibers and Polymers, vol. 13, no. 5, pp. 576-581, 2012.

[2] B. M. Cherian, A. L. Leão, S. F. De Souza et al., "Cellulose nanocomposites with nanofibres isolated from pineapple leaf fibers for medical applications," Carbohydrate Polymers, vol. 86, no. 4, pp. 1790-1798, 2011. 
[3] S. Sengupta and S. Debnath, "Studies on jute based ternary blended yarns," Indian Journal of Fibre and Textile Research, vol. 37, no. 3, pp. 217-223, 2012.

[4] M. S. Jahan, A. Saeed, Z. He, and Y. Ni, "Jute as raw material for the preparation of microcrystalline cellulose," Cellulose, vol. 18, no. 2, pp. 451-459, 2011.

[5] H. Takagi and A. Asano, "Effects of processing conditions on flexural properties of cellulose nanofiber reinforced 'green' composites," Composites Part A, vol. 39, no. 4, pp. 685-689, 2008.

[6] L. Wang, G. Han, and Y. Zhang, "Comparative study of composition, structure and properties of Apocynum venetum fibers under different pretreatments," Carbohydrate Polymers, vol. 69, no. 2, pp. 391-397, 2007.

[7] Y. Sun, L. Lin, H. Deng et al., "Structural changes of bamboo cellulose in formic acid," BioResources, vol. 3, no. 2, pp. 297-315, 2008.

[8] Y. Bulut and A. Aksit, "A comparative study on chemical treatment of jute fiber: potassium dichromate, potassium permanganate and sodium perborate trihydrate," Cellulose, vol. 20, no. 6, pp. 3155-3164, 2013.

[9] E. Sinha and S. K. Rout, "Influence of fibre-surface treatment on structural, thermal and mechanical properties of jute fibre and its composite," Bulletin of Materials Science, vol. 32, no. 1, pp. 65-76, 2009.

[10] M. S. Islam, S. Hamdan, M. R. Rahman, I. Jusoh, A. S. Ahmed, and M. Idrus, "Dynamic young's modulus, morphological, and thermal stability of 5 tropical light hardwoods modified by benzene diazonium salt treatment," BioResources, vol. 6, no. 1, pp. 737-750, 2011.

[11] H. Wang, L. Huang, and Y. Lu, "Preparation and characterization of micro- and nano-fibrils from jute," Fibers and Polymers, vol. 10, no. 4, pp. 442-445, 2009.

[12] M. R. Rahman, S. Hamdan, A. S. Ahmed et al., "Thermogravimetric analysis and dynamic Young's modulus measurement of $\mathrm{N}, \mathrm{N}$-dimethylacetamide-impregnated wood polymer composites," Journal of Vinyl and Additive Technology, vol. 17, no. 3, pp. 177-183, 2011. 

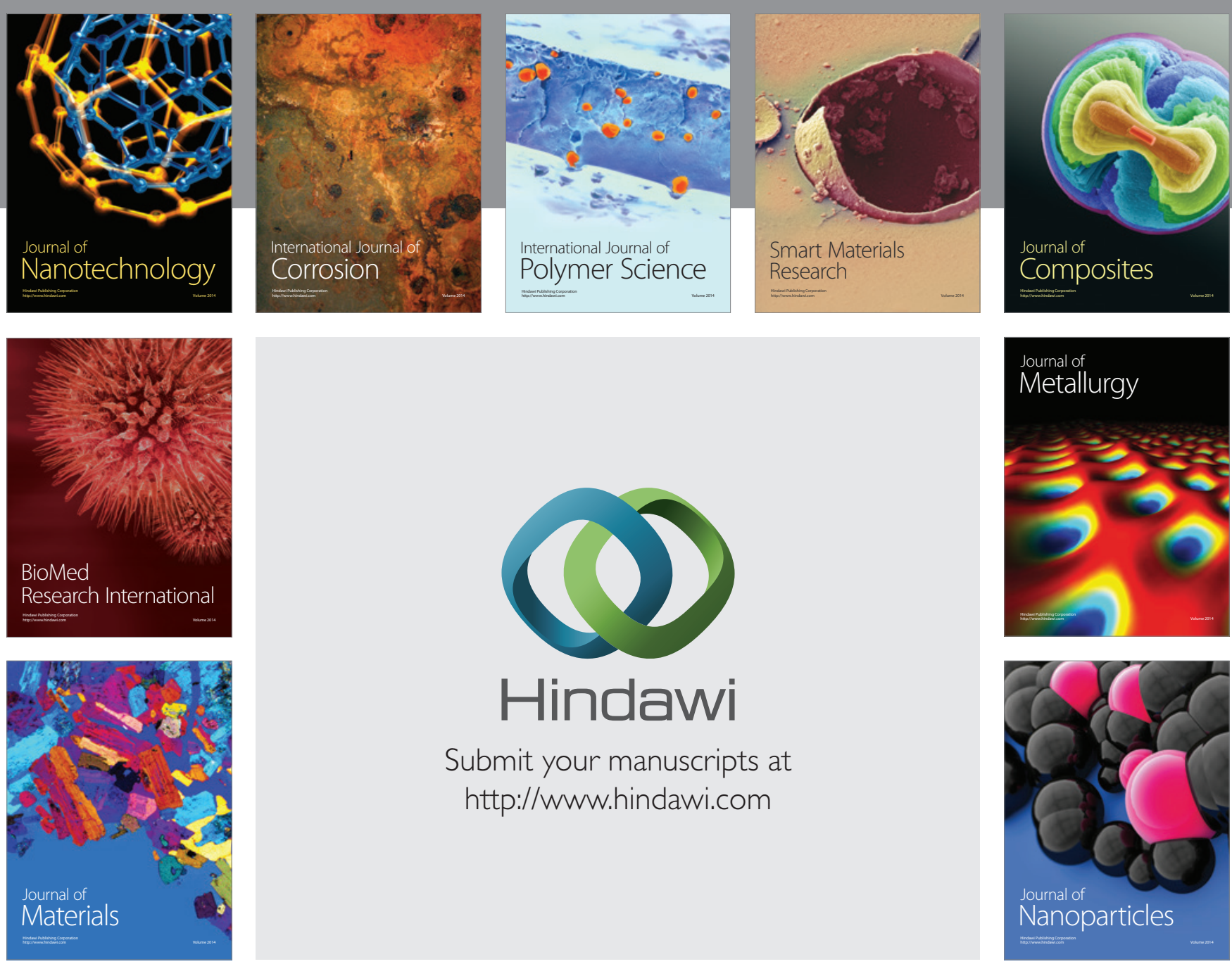

Submit your manuscripts at http://www.hindawi.com
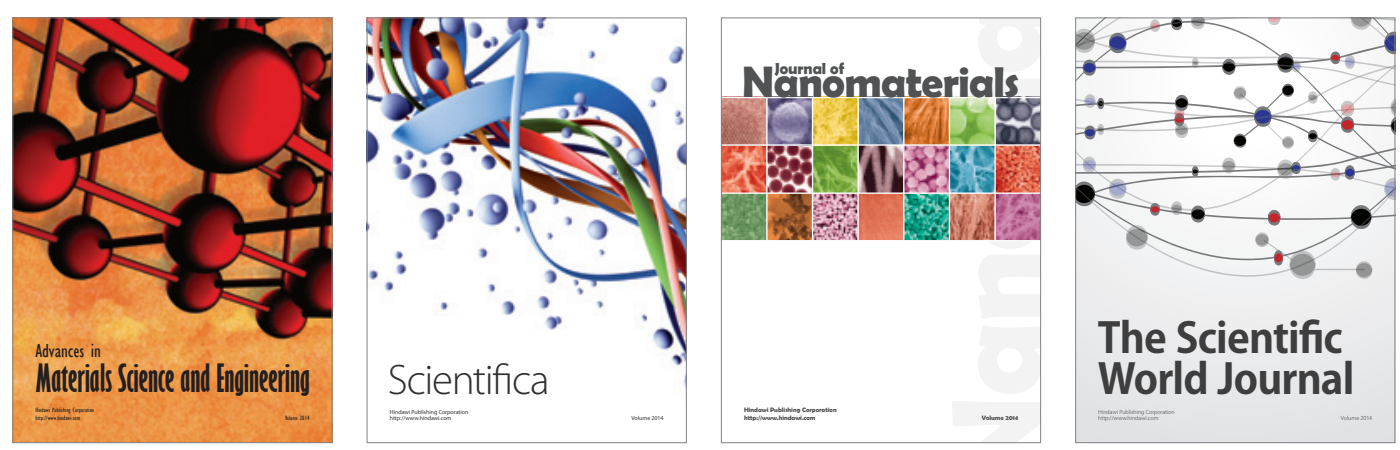

\section{The Scientific World Journal}
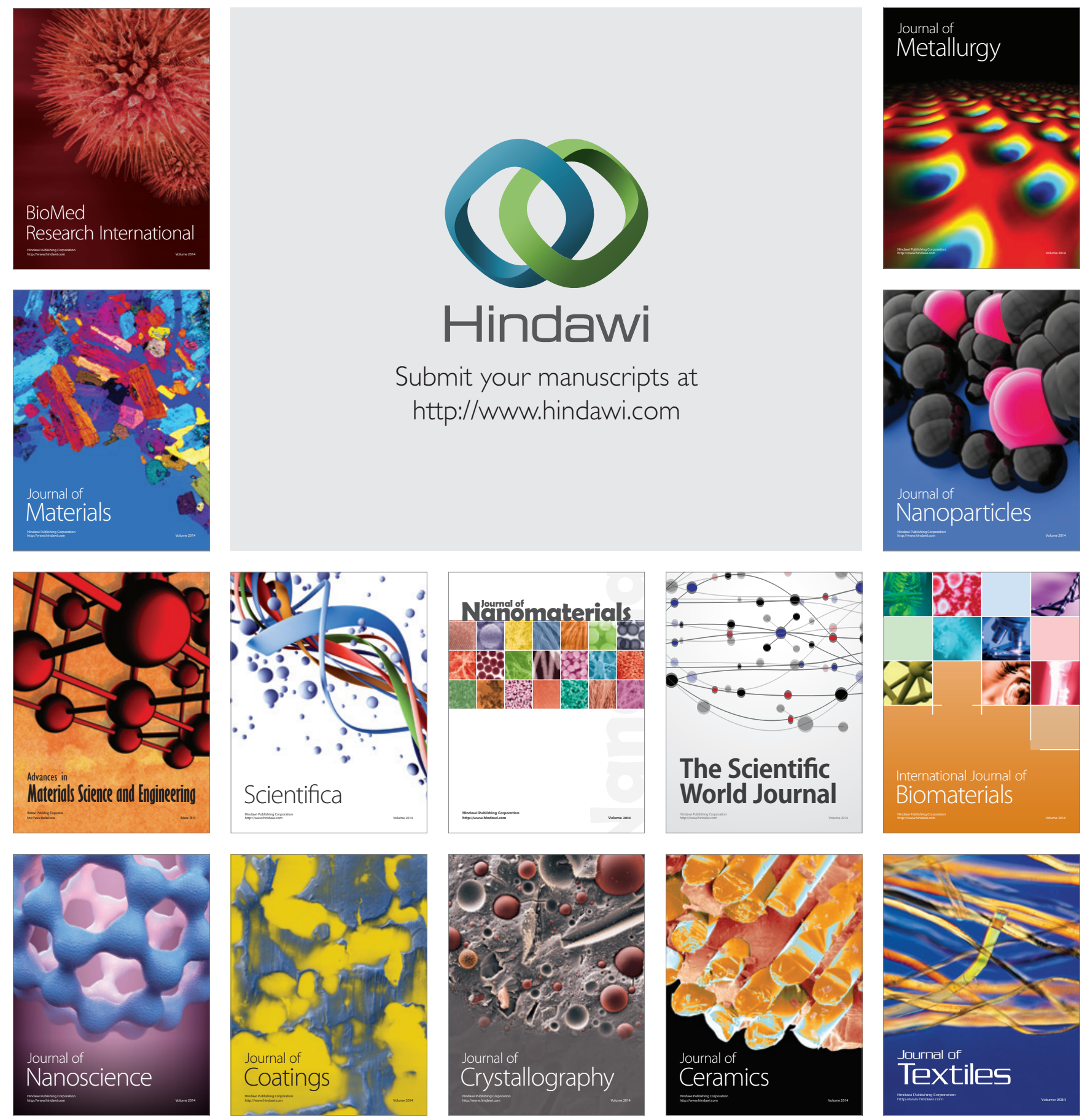